\title{
Correction to: Assessment of treatment responses in children and adolescents with Ewing sarcoma with metabolic tumor parameters derived from ${ }^{18} \mathrm{~F}-\mathrm{FDG}-\mathrm{PET} / \mathrm{CT}$ and circulating tumor DNA
}

\author{
Christian Schmidkonz ${ }^{1}$ (D) - Manuela Krumbholz ${ }^{2} \cdot$ Armin Atzinger $^{1} \cdot$ Michael Cordes $^{1} \cdot$ Theresa Ida Goetz $^{1}$. \\ Olaf Prante ${ }^{1}$. Philipp Ritt ${ }^{1}$. Christiane Schaefer ${ }^{3}$. Abbas Agaimy ${ }^{4}$ • Wolfgang Hartmann ${ }^{5}$. Claudia Rössig ${ }^{6}$. \\ Birgit Fröhlich $^{6} \cdot$ Tobias Bäuerle $^{7} \cdot$ Uta Dirksen $^{3} \cdot$ Torsten Kuwert $^{1} \cdot$ Markus Metzler $^{2}$
}

Published online: 13 February 2020

(C) Springer-Verlag GmbH Germany, part of Springer Nature 2020

\section{Correction to: European Journal of Nuclear Medicine and Molecular Imaging} https://doi.org/10.1007/s00259-019-04649-1

The original version on this paper contained an error. The author names, though correctly appeared in the PDF version, were incorrectly displayed in indexing sites. This error occurred because of the incorrect tagging of their names in the metadata of this article. The purpose of this Erratum is the correction of metadata. Therefore, indexing sites should now reflect their names as Schmidkonz C, Krumbholz M, Atzinger A, Cordes M, Goetz TI, Prante O, Ritt P, Schaefer C, Agaimy A, Hartmann W, Rössig C, Fröhlich B, Bäuerle T, Dirksen U, Kuwert T, Metzler M.

The original article has been corrected.

This article is part of the Topical Collection on Erratum

The online version of the original article can be found at https://doi.org/ 10.1007/s00259-019-04649-1

Christian Schmidkonz

christian.schmidkonz@uk-erlangen.de

1 Department of Nuclear Medicine, Friedrich-Alexander University Erlangen-Nürnberg (FAU), Erlangen, Germany

2 Department of Pediatrics and Adolescent Medicine, Friedrich-Alexander University Erlangen-Nürnberg (FAU), Erlangen, Germany

3 Pediatrics III, West German Cancer Centre, University Hospital of Essen, Essen, Germany

4 Institute of Pathology, University Hospital, Friedrich-Alexander University Erlangen-Nürnberg (FAU), Erlangen, Germany

5 Division of Translational Pathology, Gerhard-Domagk Institute of Pathology, University Hospital of Münster, Münster, Germany

6 Department of Pediatric Hematology and Oncology, University Children's Hospital Münster, Münster, Germany

7 Institute of Radiology Friedrich-Alexander University Erlangen-Nürnberg (FAU), Erlangen, Germany 